\title{
ARapid Fabrication Methodology for Payload Modules, Piloted for the Observation of Queen Honey Bees (Apis mellifera) in Microgravity
}

Rachel Soo Hoo Smith¹, Felix Kraemer ${ }^{1}$, Christoph Bader ${ }^{1}$, Miana Smith², Aaron Weber ${ }^{3}$, Dr. Michael Simone-Finstrom4, Dr. Noah Wilson-Rich ${ }^{3}$. Prof. Neri Oxman ${ }^{1+}$

${ }^{1}$ Media Lab, Department of Architecture, Massachusetts Institute of Technology, Cambridge, MA; '2Department of Mechanical Engineering, Massachusetts Institute of Technology, Cambridge, MA; ${ }^{3}$ Urban Beekeeping Laboratory \& Bee Sanctuary, Inc.; ${ }^{4}$ United States Department of Agriculture - Agricultural Research Service, Baton-Rouge, LA

Rachel Soo Hoo Smith and Felix Kraemer contributed equally to this work

Abstract

Microgravity experiment modules for living organisms have been instrumental to space research, yet their design remains complex and costly. As the private space sector enables more widely available payloads for researchers, it is increasingly necessary to design experimental modules innovatively so that they are proportionately accessible. To ease this bottleneck, we developed a rapid fabrication methodology for producing custom modules compatible with commercial payload slots. Our method creates a unified housing geometry, based on a given component layout, which is fabricated in a digital design and subtractive manufacturing process from a single lightweight foam material. This module design demonstrated a $25-50 \%$ reduction in chassis weight compared with existing models, and is extremely competitive in manufacturing time, simplicity, and cost. To demonstrate the ability to capture data on previously limited areas of space biology, we apply this methodology to create an autonomous, video-enabled module for sensing and observing queen and retinue bees aboard the Blue Origin New Shepard 11 (NS-11) suborbital flight. To explore whether spaceflight impacts queen fitness, results used high-definition visual data enabled by the module's compact build to analyze queen-worker regulation under microgravity stress ( $n=2$, with controls). Overall, this generalizable method for constructing experimental modules provides wider accessibility to space research and new data on honey bee behavior in microgravity.

Keywords

Suborbital spaceflight $\bullet$ Payload $・$ Video-enabled biological experiment $\bullet$ Honey bee queen tracking $\bullet$ Rapid manufacturing

\section{INTRODUCTION}

The private space sector is driving the unprecedented availability of modern microgravity and spaceflight experimental opportunities (Crawford, 2016). However, the feasibility of space-bound research remains limited by two factors: the need for custom modules and costs. Researchers have a limited capacity to fabricate modules that meet payload requirements as well as satisfy their specific experimental needs (Pletser and De Crombrugghe, 2017). Biological researchers face even higher barriers, as the design complexity and specialization necessary to manufacture custom modules for living organisms is an even greater challenge (Boggs and Dhiri, 2020). While services for subdivided payload platforms may offer more affordable slots, they require even further weight and volume limitations. Thus, improvements in module weight minimization and design simplicity would lead to a reduction in costs, expertise, and time necessary for payload development and would be incredibly valuable for microgravity research, including biological studies. The aim of this paper is to respond to this opportunity by providing a generalizable process for designing and fabricating custom, lightweight housing for experimental modules that foster minimal material sourcing, parts, and assembly.

The field of biological module design has made significant progress in improving accessibility. In contrast to previous initiatives, such as the ISS's 2001 Insect Habitat that demanded $\$ 2.7 \mathrm{M}$ and 2 years for preliminary development (Rock, 2002); more recent designs, such as the BioExplorer-inspired Fruit Fly Module (Inan et al., 2009) and laboratories customized for low-cost CubeSat platforms (Poghosyan and Golkar, 2017), have demonstrated increasingly efficient and versatile precedents. However, modules continue to rely on "frame and fixture" approaches, where components are individually affixed to an aluminum chassis, often through multiple customtailored fixtures and braces (Richter et al., 2010). This process requires intensive materials and parts sourcing, long turnaround times, and intricate assemblies. These challenges are further compounded by launch costs (e.g., $\sim \$ 10,000 /$ lb orbital payload 
fee) and payload specification and development factors (e.g., NanoRack's "2U" format constrains an experiment to $0.50 \mathrm{~kg}$ and $10 \times 10 \times 20 \mathrm{~cm}$ with a development time of ( 6-12 months from slot confirmation). We present a new methodology to address the challenges of both the complexities of custom experiment module design and the general payload specifications (cost of launch, weight, and dimensions) for wide-ranging experimental subject matter and function.

Our model case used in this work is an important and understudied area of space biology: the effect of microgravity on the health and reproductive viability of honey bees (Apis mellifera). Honey bees are an integral part of food production, responsible for pollinating $80 \%$ of edible flowering crops and enhancing the nutrition, yield, and shelf-life of produce beyond hand-pollination (Stein et al., 2017). These properties make honey bees promising components for supporting the regenerative food systems considered necessary for longterm space missions (Anderson et al., 2015). Importantly, one queen bee represents the laying potential of 1.3 million bees, with organs to store both male and female germlines (Nolan, 1925). A queen's fitness is a direct predictor of colony health and productivity, while reciprocally, a retinue of approximately 10 worker bee attendants is crucial for maintaining the queen's base metabolic regulation (e.g., food intake, temperature homeostasis, and excretion removal).

Tracking queen movement via behavioral observations has been the focus of previous research seeking to understand the impacts of stressors on queen and subsequent colony health (Wu-Smart and Spivak, 2016). The retinue response is also an established metric of queen quality, because the number of attendants that are attracted to a queen is largely determined by her pheromone production profile, which in turn is influenced by mating quality, reproductive status, and external stressors; thus, retinue response represents an honest indicator of a queen's fitness (Margarita et al., 2020; Rangel et al., 2016; Richard et al., 2007). Also, recent studies on the effect of temperature during long-distance transportation in migratory beekeeping have recommended that vibration, noise, and atmospheric pressure are also potential sources of stress that may contribute to colony loss (Jara et al., 2021; Melicher et al., 2019). Yet, beyond the observations of the honey bees aboard STS-13 (Vandenberg et al., 1985), which exhibited inviable eggs post-mission, no research exists on queen bee quality and fecundity in spaceflight environments.

Our work examines the intersection of these problem areas. To ease the current bottleneck in biological space research, we developed a low-cost, rapid design and fabrication methodology for modules compatible with commercial payload slots. In the Methods section, we present a computer-aided design (CAD) and subtractive manufacturing process for fabricating a custom module housing that utilizes a single lowdensity, rigid foam and occupies the payload's entire volume sans cavities for functional components. In addition, we detail a lightweight, video-enabled module using this design methodology to perform an original observational study on queen bees onboard the Blue Origin New Shepard 11 (NS-11) suborbital flight. The Results section documents our module's performance in structural evaluations, weight reduction, and ease of assembly of experimental components. Further, we analyze the video footage from the NS-11 flight to determine the regulatory capacity of honey bees in various stages of spaceflight. The data are presented as illustrative examples of data feasible on this platform, yet also may be informative to our understanding of spaceflight stressors relevant to queen bee health. Finally, we discuss the significance of this methodology's ability to address the current limitations in module design and to capture data on previously limited areas of space biology.

\section{METHODS}

\section{Design Paradigm}

The module fabrication process, depicted in Figure $1 \mathrm{~A}$, began with a digital design process performed in a $3 D$ CAD environment (Fusion 360, Autodesk; Steps 1-3). In Step 1 , the volumetric bounds of the payload were defined $(10 \times 10 \times 20 \mathrm{~cm})$ and assigned a housi ng material (e.g., foam). In Step 2, a 3D representation of each experimental component (enumerated in Figure 1B) was positioned in a layout that satisfied the functionality of the experiment (see the Subsection "Experiment Layout"). Additionally, a plane was defined that cuts through the volume such that it intersects all components, resulting in a volumetric design for two halves or sides of the housing. For experiment components producing undercuts or fragments in the housing geometry, a 3D printed brace was included in the object's footprint to simplify its geometry. In Step 3, a Boolean subtraction was performed to remove the experiment's physical and functional footprints from the housing volume, thus creating a geometry that secures them multi-directionally. Four holes were introduced perpendicular to the split line to accommodate alignment pins.

\section{Thermal Analysis}

Thermal analysis (Figure 1C) was completed using Autodesk Fusion 360's simulation capabilities. Temperature loads were applied to the battery cavity (at maximum temperature, $50^{\circ} \mathrm{C}$ ) and the heat pad $\left(\right.$ at $\left.32^{\circ} \mathrm{C}\right)$. All other components had radiation (emissivity 1 ) and convective loads applied (10 W/ $\mathrm{m}^{2} \mathrm{~K}$ for low flow air), and ambient temperature was varied in separate simulations from $20^{\circ} \mathrm{C}$ to $26^{\circ} \mathrm{C}$. 
A
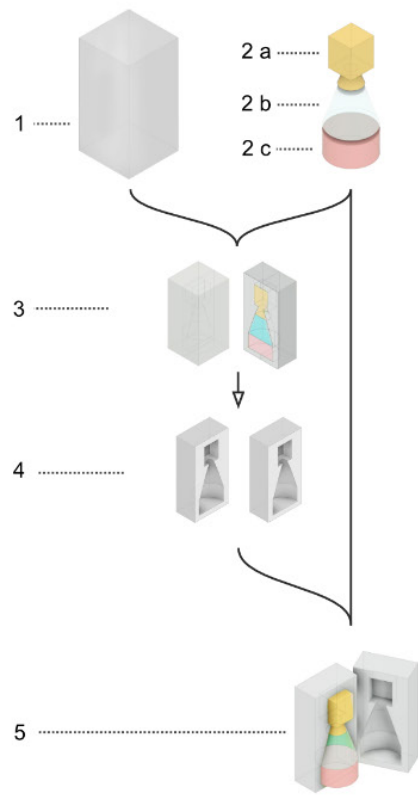

C

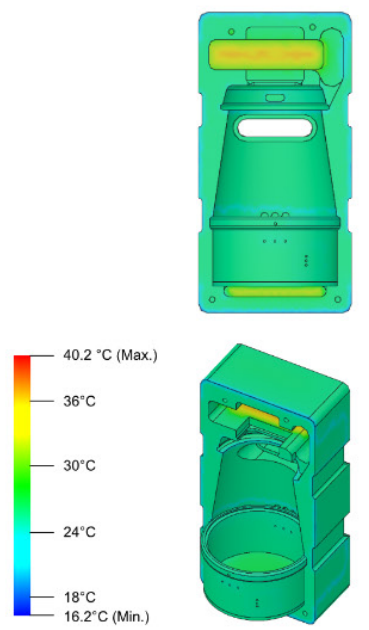

B

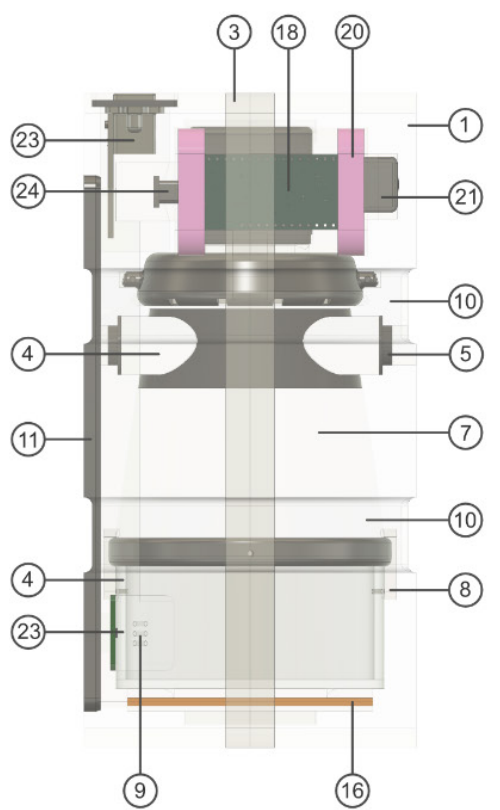

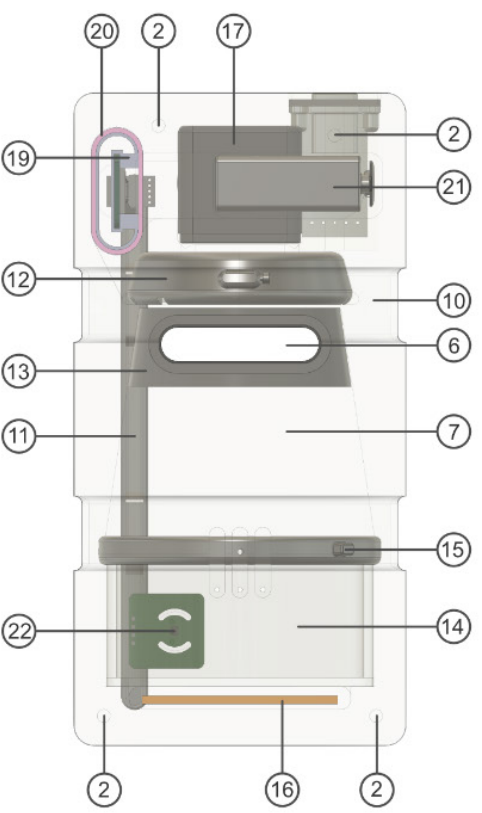

$\mathbf{E}$

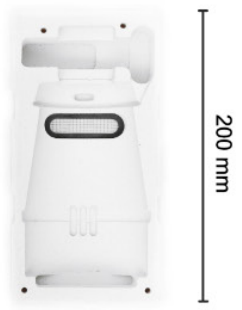

$\mathbf{F}$

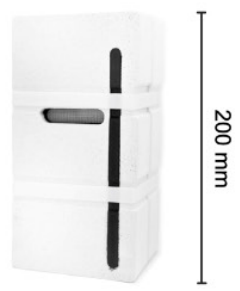

Figure 1. A generalizable method for experimental payload module design. (A) A process diagram detailing the module design and fabrication method: 1: In a CAD environment, define the available payload volume, 2: arrange experimental component according to functional interactions (e.g., a: Camera volume, b: Field of view, c: Bee compartment), and 3: subtract the experiment volume from payload volume and introduce a central split line. 4: To manufacture, use a CNC-milling machine to fabricate the two-part foam chassis. 5: To assemble, press-fit to integrate experiment components. (B) Labeled schematic of the video-enabled experimental module design: 1: Polyurethane Foam, 2: Alignment Pin ( $\times 4$, aluminum), 3: Sealing Tape, 4: Vent Cutout, 5: 3D Printed (3DP) Vent Cover, 6: Netting (insect impermeable), 7: Main Chamber, 8: Internal Air Vent ( $\times 3$, for airflow between main chamber and bee compartment), 9: Vent Holes in Bee Compartment ( $\times 9$, $1 \mathrm{~mm}$ each), 10: Groove and Silicone Band (bands not depicted for visual clarity), 11: 3DP External Cover for Cable Channel, 12: Lens Assembly (with glass macro lens and LED ring), 13: 3DP Lens Hood, 14: Bee Compartment (furnished with beeswax), 15: 3DP Bee Compartment Lid Retainer (includes $\times 4$ steel M2 screws), 16: Electric Heating Pad, 17: Camera (GoPro Hero5 Session) 18: Microcontroller/Logger (Feather Adalogger M0), 19: 3DP Holding Brace for Microcontroller, 20: Soft Foam Cushion/Antistatic Foam Tape, 21: 9V Li-lon Battery (U9VLJPBK, Ultralife), 22: Temperature/Humidity Sensor, 23: USB B Breakout Board (glued in), and 24: USB Micro Breakout Board (glued in). (C) A thermal simulation of heat generation from components of the payload module. Images display (D) payload module including all components, laid open, (E) payload module shown without electronics and bee compartment, and (F) payload module shown in closed state. CNC, computer numerical control; CAD, computer-aided design. 


\section{Fabrication}

We used a closed-cell, rigid, machinable polyurethane foam (LAST-A-FOAM FR-7106, General Plastics) for the housing. The properties of this foam, including a Federal Aviation Administration (FAA) self-extinguishing fire safety designation, are listed in Table S1. In Step 4, a 3-axis computer numerical control (CNC) router (PRSalpha, ShopBot) was used to machine the two sides of the foam housing. For each of the sides, toolpaths were created and optimized in Autodesk Fusion 360 for use of a combined single-pass operation using a $1 / 2$ " end mill (25 min machining time) and rest-machining operation using an 1/8" ball end mill (21 min machining time); shown in Figure S1. We then applied one coat of water-based paint (PW6-Spray Paint, Liquitex) to reinforce the surface. Necessary component braces were 3D printed (Onyx One, Markforged) using Onyx material.

\section{Module Assembly}

For assembly, Step 5, all experimental components (or corresponding braces) were press-fit into the chassis (Figure 1D,E). Four aluminum pins were used to align the closure of the two sides of the housing. Two silicone bands (4", Grifiti) were added within machined grooves on the exterior of the housing to secure the closure (Figure 1F).

\section{Experiment Layout}

The layout of the video-enabled module was determined largely by the minimum focal distance $(135 \mathrm{~mm})$ and field of view provided by the camera (Hero5 Session, GoPro) in combination with a macro lens $(58 \mathrm{~mm}$ HMC Close-Up Filter +4 , Hoya). Thus, the camera and the cylindrical bee compartment (clear acrylic, 2-3 mm thickness) were placed along the long axis of the payload with an unobstructed line of sight. A circular light array (24-unit Neopixel, Adafruit) was used to illuminate the interior of the bee compartment and a 3D printed lens hood was used for targeted masking of reflections caused by the surface of the bee compartment. The bee compartment was placed in direct contact with an electric heating pad (Adafruit), and in close proximity to a temperature and humidity sensor breakout board (HDC1080, Texas Instruments) in which a series of nine holes provided airflow from the bee compartment. Further, some of the bee compartments were furnished with beeswax to motivate the bees to locomote in the chamber.

All wiring for electrical components was routed via a groove in the outside surface of the module to the microcontroller (Feather M0 Adalogger, Adafruit), 9V Li-ion battery (U9VLJPBK, Ultralife), and custom circuit board that were positioned around the camera for heat isolation from live samples. A USB serial port was included for receipt of vehicle flight events and telemetric data.

\section{Module Physical Assessments}

Performance assessments were based on Blue Origin technical standards, which generally correspond to NASA's Payload Test Requirements (2018a). Test procedures are presented in Table 1. Of note, the vibration test performed did not meet NASA's Vibroacoustic Test Criteria (2017) for a random vibration environment; however, it applied an induced periodic vibration $(50 \mathrm{~Hz})$ at the overall acceptance level of acceleration, $>6.8 \mathrm{~g}$. Given that a random vibration testing facility was not available to us, the test provided an accessible method for approximating flight hardware performance in vibration environments.

\section{Queen Rearing and Insemination}

Po-line strain queen bees (Danka et al., 2016) were reared and inseminated at the USDA-ARS Baton Rouge Bee Breeding, Genetics and Physiology Laboratory. Eight newly emerged sister Po-line queens were artificially inseminated on L-30 days (days before launch). Five queens verified for fertilized egg laying were transported to the launch site on L-3 days. Pre-flight samples of sperm and hatched offspring were preserved.

\section{Biological Sample Loading, Payload Integration, and Suborbital Flight}

Two identical modules, one per "Space" queen (S1 and S2), were fabricated for use in a NanoRacks Feather Frame subdivided locker aboard flight NS-11, in addition to two modules for control queens kept at the launch site ( $\mathrm{C} 1$ and $\mathrm{C} 2$ ). Directly prior to late load, we introduced to each compartment: 1 queen, 10 attendants, and solid sugar fondant $(\sim 1 \mathrm{~g})$.

The space-bound payload modules (S1 and S2) were integrated on 5/3/2019 at 01:00 GMT-5 in preparation for subsequent launch at 08:00. During flight (captured in Videos S1 and S2 and Table S2), the modules recorded video and audio data (starting at $L+1.03 \mathrm{~m}$ ), temperature and humidity data from on-board sensors, and flight data provided from the USB data port (i.e., flight phase, IMU, altitude data). Bees were retrieved at approximately 14:00 GMT-5.

The ground control (GC) modules were kept in nearidentical housings on the launch site until the flight bees were retrieved, experiencing minimal perturbations in that time. Video recording for GC module queens $(\mathrm{C} 1, \mathrm{C} 2)$ was initiated several hours earlier than the flight modules, causing differences in the time of day of the recording ( 03:00 GMT-5), the amount of time bees had to acclimate to the container, and slight differences in module shifting or movement before recording. In addition, the bee compartments of the GC modules were not previously furnished with beeswax, and thus only smooth acrylic surfaces were exposed to the bees. Behavioral differences that may have resulted from these inconsistencies are addressed in the Sections "Results" and "Discussion." 
Table 1. Payload performance tests. Category headings are bolded.

\begin{tabular}{|c|c|c|c|c|c|}
\hline \multicolumn{6}{|c|}{ Payload performance testing } \\
\hline Test Name & Aim & Process & Min. Duration & Outcome & Output \\
\hline \multicolumn{6}{|l|}{ Mechanical } \\
\hline Static load & $\begin{array}{l}\text { Ensure payload can } \\
\text { withstand static load. }\end{array}$ & $\begin{array}{l}\geq 15 \mathrm{lb} \text { of static load applied to each } \\
\text { axis of the chassis }(x, y, z) \text { for } 2 \mathrm{~min}\end{array}$ & 2 min, per axis & \multirow{2}{*}{$\begin{array}{l}\text { Each axis was photographed before/ } \\
\text { during/after weight application; no } \\
\text { deformation or destruction of the } \\
\text { capsule is observed. } \\
\text { To incorporate the Acceleration Load } \\
\text { and Shock tests into the Static Load } \\
\text { test, } 30 \text { lbs of static load was tested } \\
\text { on each axis. }\end{array}$} & \multirow[t]{2}{*}{ Photo } \\
\hline $\begin{array}{l}\text { Accelerative load } \\
\text { and shock }\end{array}$ & $\begin{array}{l}\text { Ensure payload } \\
\text { withstands flight g-loads } \\
\text { and shock. }\end{array}$ & $\begin{array}{l}30 \mathrm{~g} \mathrm{(} \times 2 \text { nominal peak acceleration) } \\
\text { applied in the form of static load } \\
\text { force (i.e., } \times 30 \text { the weight of the } \\
\text { object) to each object. }\end{array}$ & $50 \mathrm{~ms}$ & & \\
\hline Vibration & $\begin{array}{l}\text { Ensure hardware can } \\
\text { perform in a vibration } \\
\text { environment. }\end{array}$ & $\begin{array}{l}\text { Periodic vibration, } 7.85 \mathrm{~g} \text { at } 50 \mathrm{~Hz} \\
\text { applied via Vortex Mixer (VWR, } \\
3000 \mathrm{rpm} / 4.9 \mathrm{~mm} \text { orbit), and a } \\
\text { qualitative assessment of damage } \\
\text { or displacement. }\end{array}$ & $1 \mathrm{~min}$, per axis & $\begin{array}{c}\text { No changes (damage, shifting, } \\
\text { debris) occur over the course of } \\
\text { several minutes. Note: This test is } \\
\text { not directly comparable to a random } \\
\text { vibration environment. }\end{array}$ & Video \\
\hline \multicolumn{6}{|l|}{ Thermal } \\
\hline $\begin{array}{l}\text { Touch- } \\
\text { temperature }\end{array}$ & $\begin{array}{l}\text { Ensure payload has } \\
\text { minimal thermal effect } \\
\text { on neighboring } \\
\text { experiments. }\end{array}$ & $\begin{array}{c}\text { Temperature of external faces of } \\
\text { chassis sampled by IR-camera } \\
\text { (FLIR C3, FLIR Systems) with all } \\
\text { heat-generating electrical systems } \\
\text { running for } 30 \text { min. }\end{array}$ & $\begin{array}{l}30 \mathrm{~min} \text {, or until } \\
\text { temp. plateau }\end{array}$ & $\begin{array}{c}\text { External temperature leveled at } \\
26.7^{\circ} \mathrm{C} \text { and } 31.7^{\circ} \mathrm{C} \text {, respectively, } \\
\text { with electronic heating systems and } \\
\text { battery run a maximum performance } \\
\text { for } 30 \text { min (simulating an electronic } \\
\text { "loss of control," reaching an internal } \\
\text { temperature of } 53.3^{\circ} \mathrm{C} \text { ). }\end{array}$ & $\begin{array}{l}\text { Temp. time } \\
\text { course }\end{array}$ \\
\hline \multicolumn{6}{|l|}{ Other } \\
\hline Flammability & $\begin{array}{l}\text { Ensure non-ignitable } \\
\text { or self-extinguishing } \\
\text { properties. }\end{array}$ & $\begin{array}{l}\text { Prolonged exposure to an open } \\
\text { flame, simulating an electronic or } \\
\text { battery short. }\end{array}$ & $1 \mathrm{~min}$ & $\begin{array}{l}\text { Foam held over open flame is } \\
\text { shown to self-extinguish with } \\
\text { minimal shape change or expansion; } \\
\text { corroborated by technical data sheet } \\
\text { for material. }\end{array}$ & Video \\
\hline $\begin{array}{l}\text { Fragmentation } \\
\text { (Point-of-Force) }\end{array}$ & $\begin{array}{l}\text { Ensure minimal } \\
\text { particulate in case of } \\
\text { payload fragmentation. }\end{array}$ & $\begin{array}{c}\text { Weighted chisel }(6 \mathrm{lb}) \text { dropped from } \\
1 \mathrm{~m} \text { onto the chassis, head-on and } \\
\text { top-down video used to document } \\
\text { the size and amount of particulate } \\
\text { generated. }\end{array}$ & $\mathrm{n} / \mathrm{a}$ & $\begin{array}{l}\text { Foam in contact with the sharp } \\
\text { edge broke into multiple pieces but } \\
\text { produced minimal dust. Much of the } \\
\text { module stayed intact, components } \\
\text { remained in place, and the specimen } \\
\text { compartment deflected blow without } \\
\text { damage. }\end{array}$ & Video \\
\hline
\end{tabular}

\section{Post Flight Biological Observations}

Queen bees were transported off launch site and, on $L+7$ days, introduced to three-frame miniature nucleus boxes (nucs) that are commonly used in beekeeping operations to move colonies and establish queens. Queen S2 expired on $L+14$ days due to a malfunction of the nuc container, but surviving queens were introduced to Langstroth hives, commercially standard boxes containing 10 frames for wax construction, honey storage, and larval and pupal rearing, on $L+18$ days. After 30 days, a frame of drawn comb was introduced to each colony's brood nest for 24-48 $\mathrm{h}$ to collect newly laid egg samples. Eggs samples $(n=6)$ were examined using brightfield microscopy (Wild Makroskop Optical) and imaged by digital camera (Canon 7D DSLR) and measured in ImageJ.

\section{Video Processing and Data Acquisition}

Module output data in the form of time-stamped logs of microcontroller actions were used to synchronize bee footage with sensor data, telemetry, and flight phase. Flight video data was trimmed and stabilized in Adobe After Effects. The control video for queen $\mathrm{C} 2$ was interrupted before completion and was therefore omitted. The following computational analysis was applied to video data from queens $\mathrm{S} 1, \mathrm{~S} 2$, and C1: (I) Queen Tracking: Since Queens were marked with a green dot on their thorax, we tracked this dot in video data by isolating the $G$ channel of the RGB image sequence and mapped values of the image channel such that regions with the dot have a value of 1.0 and all other regions have a value of 0.0 . Next, the centroid of the region with values of 1.0 was computed. Centroids were collected for all frames of the 18:45 min sequences and connected to a trajectory visualizing the path of the queen during the experiment. (II) Bee Spatial Distribution Diagram: As the backgrounds throughout the experiments were static, we separated the background from the foreground, showing the motion of the bees through background subtraction. We encoded the foreground of bees as pixels with value of 1.0 and the background as pixels with value of 0.0 . For all images in the sequence, we added the 
images to a frame buffer that accumulated values over the video duration. Once completed, all values were normalized to a range from 0.0 to 1.0 and assigned a heatmap color per pixel. (III) Cluster Area Measurement: For each of the background-subtracted frames, we estimated the cluster area of the bees by adding the 1.0 pixels and diving by the relative pixel area, estimated from the experiment dimensions. The values were plotted over time. (IV) Queen Distance-FromCluster-Centroid Measurement: We used the spatial position of the queen, as computed in the queen tracking step, and estimated the centroid of the bee cluster, as described in the bee spatial distribution diagram step. The distance of the spatial position of the queen to the cluster centroid was then plotted over time.

\section{RESULTS}

First, the results provide an evaluation of the module design through: (i) validation of performance to technical standards, (ii) demonstration of weight reduction compared to traditional methods, and (iii) ease of assembly and installation of living specimens (Figure 1). Second, the results demonstrate biological experimental success via autonomous support and monitoring of honey bee specimens during the NS-11 flight and the generation of new data on queen-worker behavior in microgravity (Figure 2).

For validation of performance to technical standards, the module design methodology (Figure 1A) successfully demonstrated a new type of lightweight foam chassis that acted as a multidirectional housing for all functional components while also providing shock absorption, thermal and electrical insulation, and fire retardation. Payload specifications require housing to withstand nominal and non-nominal static and dynamic forces, serve as a physical enclosure, and protect all experimental components from vibrations, shifting, or becoming unanchored during flight. Our chassis comprised a rigid polyurethane foam (FR-7106, General Plastics) machined in a split-form that snugly held each internal component in place and additionally offered vibrational dampening and electrical insulation. In Table 1 , the chassis satisfied a panel of payload tests requirements for static and dynamic load ( $\leq 30 \mathrm{lb}$ force), vibration $(7.85 \mathrm{~g}$ at $50 \mathrm{~Hz}$ frequency), heat transfer (non-significant), flame (selfextinguishing), and dust formation (non-significant).

In demonstration of weight reduction, our $2 \mathrm{U}$-form-factor chassis (machined from a foam density of $96 \mathrm{~kg} / \mathrm{m}^{3}$ and coated in a protective paint) weighed $0.13 \mathrm{~kg}$. Importantly, our chassis also functioned holistically as the frame, fixtures, and walls, leaving all but $26 \%$ of payload weight to the experiment. By contrast, existing $2 \mathrm{U}$ payloads have achieved a bare-frame weight of $0.16-0.28 \mathrm{~kg}(32-55 \%$ of the total payload weight) not including the required fixture hardware or wall panels (NASA, 2018b).

Regarding ease of assembly, our method enabled toolless and reversible press-fit assembly of all experimental components, which proved markedly beneficial to the rapid loading and retrieval of biological samples. Illustratively, we generated a platform for conducting an autonomous biological experiment for inclusion in a NanoRacks Feather Frame subdivided payload for suborbital spaceflight. The completed assembly, detailed in Figure 1B and Table 2, comprised over 24 interrelated components organized to initiate and perform stabilized video monitoring of an experiment chamber, closedloop temperature control, and data logging from internal sensors and flight telemetry. At handoff (L-30 days), the housing was closed via press-fit, guided by four alignment pins, and fastened with two silicone bands in machined grooves (Figure 1D-F); during a late load, hours prior to launch (L-0 days $7 \mathrm{~h}$ ), the assembly was easily reopened without tools and honey bee samples were rapidly loaded.

Finally, in demonstration of biological experiment execution, two space-bound modules performed an autonomous experimental program during spaceflight: each monitored internal temperature and humidity continuously and recorded $18.75 \mathrm{~min}$ of countdown-triggered audiovisual data of subjects S1 and S2 $(2.7 \mathrm{~K} / 2704 \times 1520$ pixels, $60 \mathrm{fps}$, stabilized; Figure $2 \mathrm{~A}$, SI Video 1). The module experienced a 3.1-minute micro-gravitational arc $(<0.1 \mathrm{G})$ and up to $6.5 \mathrm{G}$ during descent. Results used visual data to analyze queenworker capacity for homeostatic regulation under microgravity and flight stress, compared to grounded controls $\mathrm{C} 1$ and C2. Consistent with prevailing entomological methods to determine queen bee health (Slessor et al., 1988; Vergoz et al., 2009), video data was first analyzed for bee spatial distribution (Figure 2B,C) and queen tracking (Figure 2D). Then, as a proxy for retinue formation, we derived retinue area (cluster area per timepoint) and queen distance (distance of the queen from on the mean center of the cluster). Figure $2 \mathrm{E}$ and $\mathrm{F}$ pairs flight data (velocity, acceleration, altitude, flight stage) with the retinue area and queen distance of subjects $\mathrm{S} 1, \mathrm{~S} 2$, and $\mathrm{C} 1$.

We used the queen distance measurement (Figure 2F, orange line), in conjunction with an established definition for the active retinue ellipse as a $\leq 1.5 \mathrm{~cm}$ distance from the queen (Kaminski et al., 1990, orange dashed line), to establish that nominal retinue distance was exhibited by the mean bee cluster for periods of time in both flight and GC modules. However, certain flight events caused observable disruptions to the retinue. Notably at $t=8.35 \mathrm{~min}$, main chute deployment (Flight code: J) induced a shock force and increased queen distance in both $\mathrm{S} 1$ and $\mathrm{S} 2$, persisting for $\sim 3-5 \mathrm{~min}$, indicating that this event may be an important short-term stressor to queens. S2 showed increased queen distance for much of the 
A

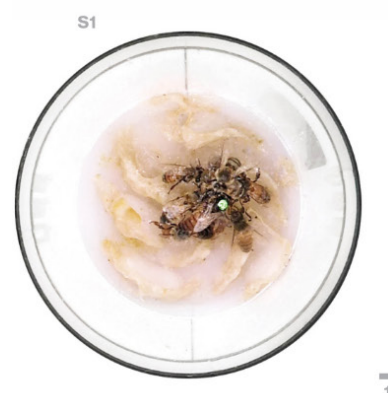

B

Bee Distribution Over Space
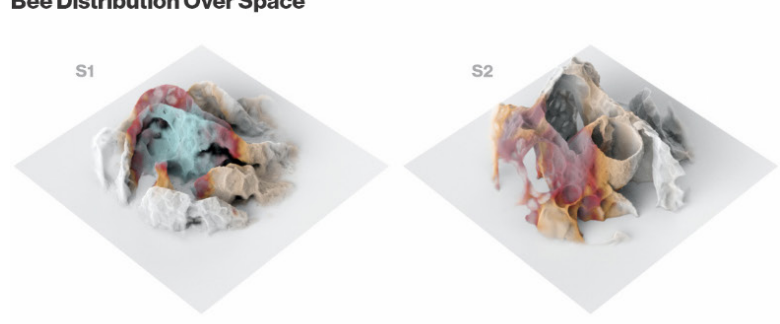

C

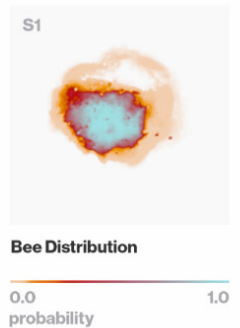

D

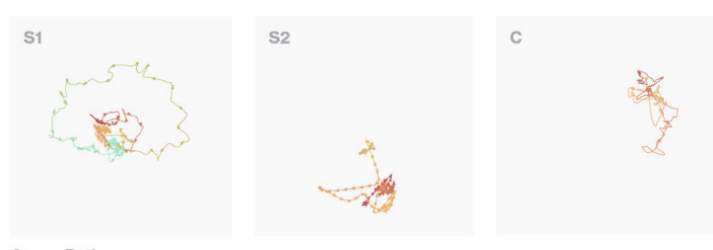

Queen Path
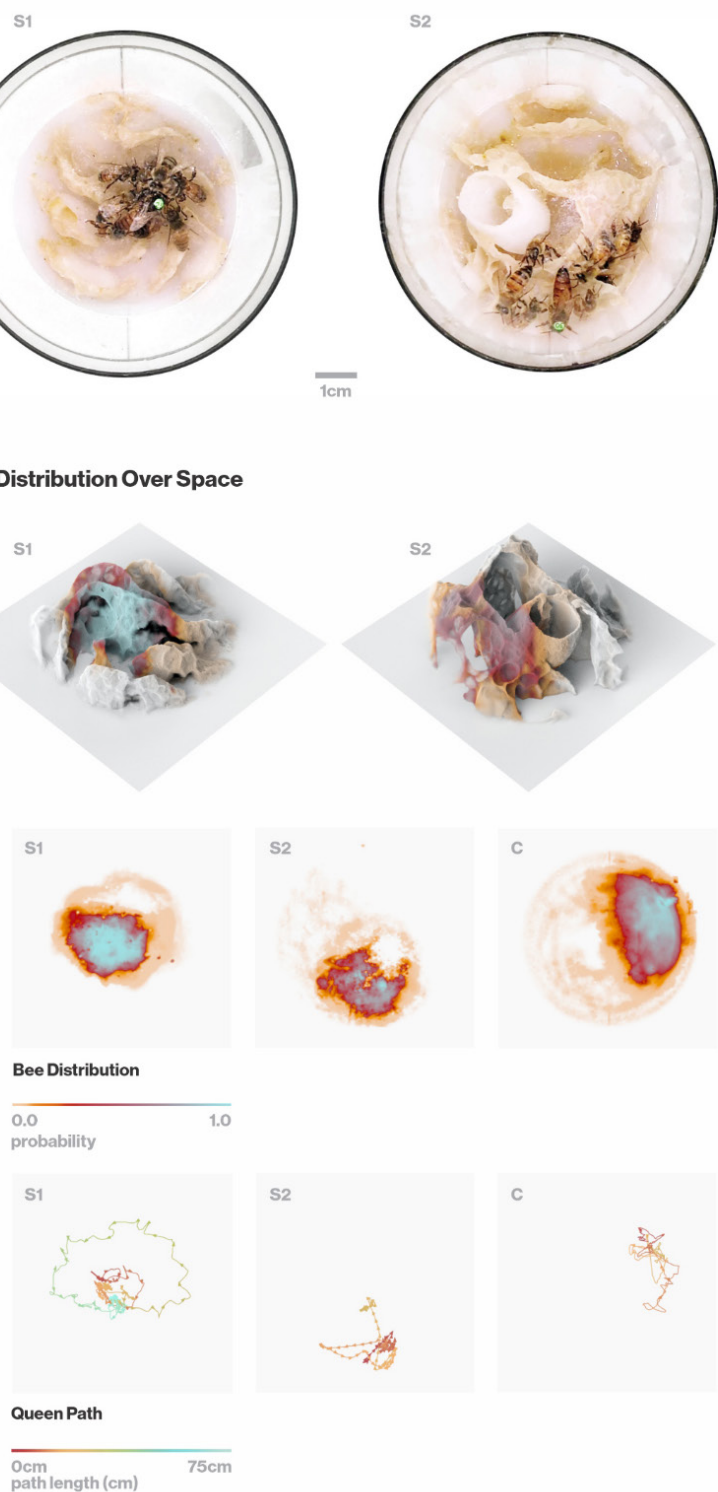

E

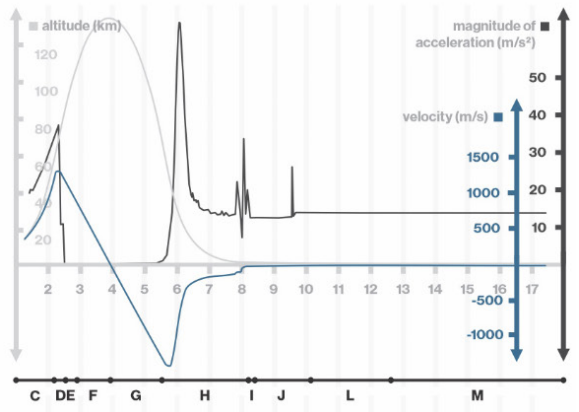

F
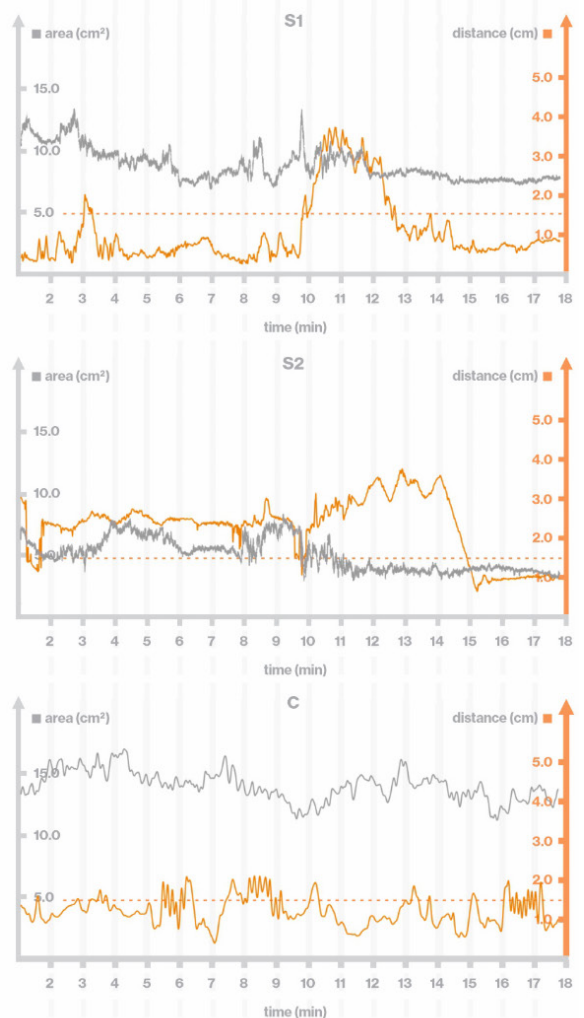

Figure 2. Analysis of video data for queen and retinue bee regulatory mechanics during suborbital flight. (A) A video frame from each space-bound module at a sample timepoint during flight; queens S1 and S2 each bear a green dot on their thorax, while 10 worker bees per module form a retinue (for full video, see SI Video 1). (B-F) Quantification of queen and retinue behavior was derived through several computational video analysis techniques: (B) Bee Spatial Distribution within the compartment was calculated from video data by assigning a value of 1.0 to pixels containing bees per each frame and 0.0 elsewhere, and summing values over all frames $(L+0 \mathrm{~m}$ to $L+18.75 \mathrm{~m})$. Values were normalized to a range from 0.0 to 1.0 and assigned a heatmap color; subsequently, this was mapped to the 3D topology of the beeswax-furnished compartment for S1 and S2, and (C) also displayed in a 2D format for comparison of S1, S2, and control C1. (D) Queen Tracking, obtained by isolating the $G$ channel of the RGB image sequence and mapping the trajectory of the green marker sequentially across all frames, visualized the 2D path of queens during the flight; this was assigned a color gradient according to arc length for comparison of S1, S2, and C1 queen paths. (E) Data-logged IMU and flight phase data are translated to altitude ( $\mathrm{m}$, gray line), velocity (m/s, blue line), and acceleration force $\left(\mathrm{m} / \mathrm{s}^{2}\right.$, black line) per $1 \mathrm{~s}$ time increments and graphed over time. Letter Codes correspond to flight phases in Table S2. (F) Cluster Area Measurement ("retinue area," gray line) and Queen Distance-From-Cluster-Centroid Measurement ("queen distance," orange line) are respectively calculated by determining total area of bee-occupied pixels per frame and measuring distance from the centroid of the total bee area to the centroid of the queen dot per frame. Each is plotted over time for S1, S2, and C1 queens as a proxy for maintenance of nominal retinue formation around the queen. As a benchmark for Queen Distance-From-Cluster-Centroid values, a common definition for retinue ellipse establishes $\leq 1.5 \mathrm{~cm}$ (orange dashed line) as the nominal distance from a queen to an attending retinue. 
Table 2. Experimental module weight allotment. Category headings are bolded; in-line bolded values represent the summed weight (g) of the components within that category (listed below the heading), followed in parenthesis by the weights' percentage out of the of the maximum weight limit. The total experimental module weight was $439.6 \mathrm{~g}$, with $59.4 \mathrm{~g}$ of unallotted weight remaining.

\begin{tabular}{|c|c|c|c|c|c|}
\hline \multicolumn{6}{|c|}{ Maiden flight $2 \mathrm{U}$ payload module characteristics $(\mathrm{L}=102 \mathrm{~mm}, \mathrm{~W}=102 \mathrm{~mm}, \mathrm{H}=200 \mathrm{~mm}$ ) } \\
\hline Item & Bulk weight & Unit & Amount & Unit & Weight $(g)$ \\
\hline Housing components & & & & & $146.6(29 \%)$ \\
\hline Foam housing (not including coating) & 0.096 & $\mathrm{~g} / \mathrm{cm}^{3}$ & 1,226 & $\mathrm{~cm}^{3}$ & 117.7 \\
\hline Paint coating & & & & & 16.0 \\
\hline Silicon straps & 6.45 & g & 2 & pcs & 12.9 \\
\hline Electronic and video components & & & & & $211.4(42 \%)$ \\
\hline GoPro Hero5 Session & 72.3 & g & 1 & Pcs & 72.3 \\
\hline Lens & 40.6 & g & 1 & pcs & 40.6 \\
\hline Battery & 37.0 & g & 1 & pcs & 37.0 \\
\hline Wires & 20.0 & g & 1 & pcs & 15.0 \\
\hline USB connector & 12.0 & g & 1 & pcs & 12.0 \\
\hline Lens assembly & 10.0 & g & 1 & pcs & 10.0 \\
\hline NeoPixel Ring LED light & 6.2 & g & 1 & pcs & 6.2 \\
\hline Custom connector board & 6.0 & g & 1 & pcs & 6.0 \\
\hline Feather Adalogger & 5.5 & g & 1 & pcs & 5.5 \\
\hline Heating pad & 3.8 & g & 1 & pcs & 3.8 \\
\hline Sensors board (temp and humidity) & 3.0 & g & 1 & pcs & 3.0 \\
\hline Bee compartment & & & & & $81.6(16 \%)$ \\
\hline Acrylic compartment (including lid) & 1.185 & $\mathrm{~g} / \mathrm{cm}^{3}$ & 50 & $\mathrm{~cm}^{3}$ & 59.3 \\
\hline Beeswax & 20.0 & gr & 1 & pcs & 20.0 \\
\hline Worker bees & 0.113 & gr & 10 & pcs & 1.1 \\
\hline Queen bee & 0.193 & gr & 1 & pcs & 0.2 \\
\hline Solid sugar fondant & 1.0 & $\mathrm{gr}$ & 1 & pcs & 1.0 \\
\hline Total weight & & & & & $439.6(88 \%)$ \\
\hline Max. weight & & & & & 499.0 \\
\hline
\end{tabular}

flight time, yet the queen distance may have been impacted by the 3D beeswax topology of the bee compartment. From video footage and the retinue area measurement (Figure 2F, gray line), we observed that $\mathrm{C} 1$ worker bees wandered more generally and exhibited larger retinue area, while the flight worker bees (S1 and S2) clustered tightly. Tight grouping and lower mobility may be indicators of worker bees exhibiting stress and/or protective behavior toward the queen in the flight environment. However, differences in worker bee clustering behaviors may have also been impacted by the presence of beeswax structures. Post-flight, while egg size (a predictor of hive health) did exhibit a statistically significant difference in diameter from queens S1 and C1 ( $n=6, \mathrm{Cl} 95 \%, p=p=0.014)$, all observed eggs hatched into healthy offspring (Figure S3).

Overall, we delineate the merits of our generalizable module design: (i) The unified foam chassis provided positioning and securement for a plurality of module components and met structural and insulative spaceflight performance requirements; (ii) The design exhibited a weightminimized chassis and thereby provided an unprecedented weight reallocation to experimental components, such as those commonly omitted due to miniaturization constraints; (iii) All components could be rapidly disassembled and reassembled for pre-flight checks and also for biological sample loading and retrieval. Finally, we documented original results from the autonomous experiment module and biological habitat for honey bees through take-off, microgravity, re-entry, and postflight conditions.

\section{DISCUSSION}

Presently, it is a priority of public and private space organizations to expand the opportunities available to researchers to identify 
processes that are uniquely possible under microgravity (NASA, 2019). Moreover, biological experiments have been crucial to foundational research into long-term space operations-from investigating engineered food chains (Fischer and Laforsch, 2018) to addressing space radiation (Shunk et al., 2020) and human physiology in microgravity (Walls et al., 2020). Our experimental module was a first of its kind for insect space studies, and our platform provides an accessible format that can be easily adapted or augmented for future launches. Below, we discuss our contributions to general payload fabrication, video observation modules, and honey bee research.

Researchers are tasked with building custom payloads for experimental modules while adhering to performance requirements under weight and dimensional constraints. This high barrier to entry can be rethought to create generalizable design regimes using ubiquitous tools, inexpensive materials, and minimal parts. We created a design process that can be reproduced through a simple machining step with tools that are common to makerspaces. The CAD environment used to model the unified chassis simultaneously provided an intuitive way to layout design components and supported simulations of weight and thermal analysis before manufacturing (Figure 1C). Moreover, by using a press-fit assembly regime, the amount and complexity of housing hardware did not scale with the number of components. Thus, this method lowers the barriers of mechanical expertise and time, invites more diverse researchers, and provides the opportunity to test multiple iterations in the allotted development timeline.

Among the challenges of compacting a series of experimental capabilities, weight limits have heretofore curtailed the types and sensitivity of experimental equipment, including video quality (Cho et al., 2019). In the $2 \mathrm{U}$ experimental platform presented here, the design supports notably high image resolution $(\leq 4 \mathrm{~K} / 3840 \times 2160$ pixels, equating to $0.05 \mathrm{~mm}$ resolution per pixel at the platform's focal distance), high frame rate ( $\leq 100 \mathrm{fps}$ ), and/or stabilization for video footage. This was achieved by modifying a compact consumer-grade camera solution (Hero5 Session, GoPro), using an analog switch to connect between the camera's solid-state shutter release and the onboard microcontroller (see Video S3 and SI Methods). Combined with emerging computational image analysis and machine learning processing, compact high-definition video modules are a powerful and versatile tool for space experimentation, and especially so for biological specimens.

At the level of honey bee research, while there are precedents for individual bumblebees (Yamashita et al., 2010) and a mature hive (Vandenberg et al., 1985) being brought to space, no prior missions have specifically studied the queen in relation to the effects of space transport. NASA mission STS-13 of 1984 reported on housing a hive in microgravity for 7 days and noted that eggs laid by the queen in the orbiter failed to hatch after the mission's return, raising many questions about bee reproductive viability (Vandenberg et al., 1985). By contrast, a queen in our study was able to lay viable eggs after spaceflight. However, due to limited subjects $(n=2)$ and flight duration, much is still unknown.

In addressing our experiment's limitations, we acknowledge that disparities between the GC and flight modules limited our ability to isolate causation of certain behaviors. The lack of beeswax in the $\mathrm{C} 1$ bee compartment created a less variable $3 \mathrm{D}$ space and a foreign surface material for the control bees, which could have impacted movement of bees as well as bees' ability to thermoregulate or sense pheromone signals-as beeswax is a known medium for pheromone transduction (Yang et al., 2010). Yet, past literature on queen transport indicates that the absence of wax in short timeframes is not a major determining factor in long-term outcomes of queen quality (Withrow et al., 2019). We suggest that future experiments improve control setups, use pre- and post-flight recordings as datapoints, expose bees to analogue vibration environments in ground studies, and include additional sensors (e.g., $\mathrm{CO}_{2}$ and volatile organic compound monitors, thermal imaging) to facilitate a richer analysis of the metabolic and pheromonal state of queen and retinue bees during flight.

Looking to the future, the platform presented here can help facilitate the expanded use of portable videographic recording and analyses techniques to track both retinue and queen movement in a broader array of studies to gain detailed information that is useful for determining both queen quality and the impacts of queen status on colony health in both traditional apiculture and space environments (Vergoz et al., 2009). Previous work on queen reproductive health in relation to transportation has focused on temperature as the major factor in queen health and subsequent productivity in the context of commercial pollination services and queen breeder shipments (Melicher et al., 2019; Withrow et al., 2019). In furtherance of the field, this study focused on differential gravitational, vibrational, and shock forces as sources of temporary retinue disruption, where temperature was held relatively constant. Thus, this research advances the technology readiness level for proposals of longer flight missions to further uncover insights into regulatory and reproductive functions in microgravity and whether bees may participate in our long-term space survival.

\section{CONCLUSION}

In conclusion, the generalizable method presented for constructing experimental modules provides broader accessibility to space research and new data on honey bee 
behavior in microgravity. This module design demonstrated a $25-50 \%$ chassis weight reduction compared to the state-ofthe-art, and improvements in manufacturing time, simplicity, and cost that make space research more accessible to researchers. We further demonstrate that autonomous, video-enabled modules produced by this methodology can support and observe living specimens aboard suborbital flight and capture high-definition visual data on previously limited areas of space biology.

\section{ACKNOWLEDGMENTS}

This work was supported by the Robert Wood Johnson Foundation (RWJF, grant no. 74479) and GETTYLAB. The authors thank GETTYLAB and the RWJF for their generous support of our scientific research into new material ecologies; Dr. Ariel Ekblaw of the MIT Space Exploration Initiative, which this work is a part of; Gabriel Owens-Flores; and Julia Wolfenbarger, Jacob Scoccimerra, and the NanoRacks and Blue Origin support teams that helped enable this module. We additionally thank Garrett Dodds for producing the queens used for this study, and the beekeepers Michael Duchouquette of Zumbido Farms, Ren Ri, and Best Bees Inc., who cared greatly for our bees.

\section{COMPETING INTERESTS}

All authors declare that they have no competing interests. It is noted that R.S.S., F.K., and N.O. are authors on a patent application filed by the Massachusetts Institute of Technology that describes methods similar to those described in this work (US application no. 63047248).

\section{REFERENCES}

Anderson MS, Ewert MK, Keener JF, Wagner SA (2015). Life support baseline values and assumptions document. Nasa/Tp-2015218570 1-220. https://doi.org/CTSD-ADV-484 A.

Boggs C, Dhiri $V$ (2018) Identification of user needs and possible platforms for future microgravity and space experimentation. SpaceOps Conferences. https://doi.org/10.2514/6.2018-2694.

Cho DH, Choi WS, Kim MK, Kim JH, Sim E, Kim HD (2019) Highresolution image and video CubeSat (HIREV): Development of space technology test platform using a low-cost CubeSat platform. International Journal of Aerospace Engineering. https:// doi.org/10.1155/2019/8916416.

Crawford IA (2016) The long-term scientific benefits of a space economy. Space Policy 37, 58-61. https://doi.org/10.1016/j. spacepol.2016.07.003.
Danka RG, Harris JW, Dodds GE (2016) Selection of VSH-derived "Pol-line" honey bees and evaluation of their Varroa-resistance characteristics. Apidologie 47, 483-490. https://doi.org/10.1007/ s13592-015-0413-7.

Fischer J, Laforsch C (2018) The influence of gravity and light on locomotion and orientation of Heterocypris incongruens and Notodromas monacha (Crustacea, Ostracoda). npj Microgravity 4 , 1-9. https://doi.org/10.1038/s41526-017-0037-5.

Inan OT, Etemadi M, Sanchez ME, Marcu O, Bhattacharya S, Kovacs GTA (2009) A miniaturized video system for monitoring the locomotor activity of walking drosophila melanogaster in space and terrestrial settings. IEEE Transactions on Biomedical Engineering 56, 522-524. https://doi.org/10.1109/TBME.2008.2006018.

Jara L, Ruiz C, Martín-Hernández R, Muñoz I, Higes M, Serrano J, De la Rúa $P$ (2021) The effect of migratory beekeeping on the infestation rate of parasites in honey bee (Apis mellifera) colonies and on their genetic variability. Microorganisms 9, 1-18. https:// doi.org/10.3390/microorganisms9010022.

Kaminski LA, Slessor KN, Winston ML, Hay NW, Borden JH (1990) Honeybee response to queen mandibular pheromone in laboratory bioassays. Journal of Chemical Ecology 16, 841-850. https://doi. org/10.1007/BF01016494.

Margarita O, Osnat M, Abraham H (2020) Choosing the best: Honeybee workers can assess reproductive quality of the queen through pheromonal signalling in simultaneous choice assays. Apidologie 51, 291-306. https://doi.org/10.1007/s13592-019-00712-w.

Melicher D, Wilson ES, Bowsher JH, Peterson SS, Yocum GD, Rinehart JP (2019) Long-distance transportation causes temperature stress in the honey bee, Apis mellifera (Hymenoptera: Apidae). Environmental Entomology 48, 691-701. https://doi. org/10.1093/ee/nvz027.

NASA (2019) Forecasting future NASA demand in low-earth orbit: Revision two-quantifying demand prologue.

NASA (2018a) NASA-STD-7002B payload test requirements. NASA Tech. Stand. Off. NASA Chief Eng.

NASA (2018b). State of the art small spacecraft technology.

NASA (2017). NASA payload vibroacoustic test criteria. NASA Tech. Stand. Off. NASA Chief Eng. 8-39.

Nolan WJ (1925) The brood-rearing cycle of the honeybee. US Department of Agriculture.

Pletser V, De Crombrugghe G (2017) Emerging microgravity platforms and their capabilities compared to the traditional offering, 67th International Astronautical Congress (IAC).

Poghosyan A, Golkar A (2017). CubeSat evolution: Analyzing CubeSat capabilities for conducting science missions. Progress in Aerospace Science 88, 59-83. https://doi.org/10.1016/j. paerosci.2016.11.002.

Rangel J, Böröczky K, Schal C, Tarpy DR (2016) Honey Bee (Apis mellifera) queen reproductive potential affects queen Mandibular Gland Pheromone Composition and Worker Retinue Response. PLoS One 11, e0156027. https://doi.org/10.1371/journal. pone. 0156027. 
Richard FJ, Tarpy DR, Grozinger CM (2007) Effects of insemination quantity on honey bee queen physiology. PLoS One 2, e980. https://doi.org/10.1371/journal.pone.0000980.

Richter RC, Morrow RC, Remiker RW (2010) Reconfiguration of animal and plant habitat payloads for gravitational biology research. https://doi.org/10.2514/6.2010-6235.

Rock A (2002) Canadian Space Agency Performance Report For the period ending March 31, 2002, Minister of Public Works and Government Services Canada. https://doi.org/10.1057/978-1-34995988-4 228.

Shunk G, Gomez X, Averesch N (2020) A self-replicating radiationshield for human deep-space exploration: Radiotrophic fung can attenuate ionizing radiation aboard the International Space Station. bioRxiv 2020.07.16.205534. https://doi. org/10.1101/2020.07.16.205534.

Slessor KN, Kaminski LA, King GGS, Borden JH, Winston ML (1988) Semiochemical basis of the retinue response to queen honey bees. Nature 332, 354-356. https://doi.org/10.1038/332354a0.

Stein K, Coulibaly D, Stenchly K, Goetze D, Porembski S, Lindner A, Konaté S, Linsenmair EK (2017) Bee pollination increases yield quantity and quality of cash crops in Burkina Faso, West Africa. Scientific Reports 7, 17691. https://doi.org/10.1038/s41598-01717970-2.

Vandenberg JD, Massie DR, Shimanuki H, Peterson JR, Poskevich DM (1985) Survival, behavior and comb construction by honey bees, Apis Mellifera, in zero gravity aboard NASA Shuttle Mission STS-13. Apidologie 369-384. https://doi.org/10.1051/ apido:19850402.

Vergoz V, McQuillan HJ, Geddes LH, Pullar K, Nicholson BJ, Paulin MG, Mercer AR (2009) Peripheral modulation of worker bee responses to queen mandibular pheromone. Proceedings of National Academy of the Sciences. 106, 20930-20935. https://doi. org/10.1073/pnas.0907563106.

Walls SM, Diop S, Birse R, Elmen L, Gan Z, Kalvajuri S, Reddy C, Taylor E, Trinh B, Vogler G, Zardnt R, McCulloch A, Lee P, Bhattacharya S, Bodmer R, Ocorr K (2020) Prolonged exposure to microgravity reduces cardiac contractility and initiates remodeling in drosophila. Cell Reports https://doi.org/10.2139/ssrn.3667140.

Withrow JM, Pettis JS, Tarpy DR (2019) Effects of temperature during package transportation on queen establishment and survival in honey bees (Hymenoptera: Apidae). Journal of Economic Entomology 112, 1043-1049. https://doi.org/10.1093/jee/toz003.

Wu-Smart J, Spivak M (2016) Sub-lethal effects of dietary neonicotinoid insecticide exposure on honey bee queen fecundity and colony development. Scientific Reports 6, 1-11. https://doi. org/10.1038/srep32108.

Yamashita M, Hashimoto H, Mitsuhata M, Sasaki M (2010) Flight performance of bumble bee as a possible pollinator in space agriculture under partial gravity. 38th COSPAR Scientific Assembly. Held 18-15 July 2010, Bremen, Ger. p.6 38, 6.
Yang MX, Tan K, Radloff SE, Pirk CWW, Hepburn HR (2010) Heterospecific queen retinue behavior of worker bees in mixed-species colonies of Apis cerana and Apis mellifera. Apidologie 41, 54-61. https://doi.org/10.1051/apido/2009047. 